\title{
PENDIDIKAN DAN PERSEPSI IBU HAMIL DALAM MELAKUKAN KUNJUNGAN K4 DI DESA PINGGIR PAPAS KECAMATAN KALIANGET KABUPATEN SUMENEP
}

\author{
Ratna Indriyani, Program Studi Kebidanan UNIJA Sumenep \\ e-mail: zhafiranourya@gmail.com \\ Dian Ika Puspitasari, Program Studi Ilmu Keperawatan UNIJA Sumenep \\ e-mail: dianika.uwr@gmail.com
}

\begin{abstract}
Pregnancy or antenatal care $(A N C)$ is highly recommended for pregnant women to monitor maternal and fetal health in the womb to avoid problems and complications. One of the ways to detect maternal and fetal complications is $K 4$ coverage. $K 4$ coverage is used as an indicator to know the range comprehensive antenatal care and assess the level of protection against pregnant women. The low coverage of K4 visits in the third trimester of pregnant women is influenced by several factors, that is predisposing factors (education, perception and knowledge), supporting factors (availability of health facilities) and (attitude and behaviour of health workers). This study was determine to the general education description and perception of third trimester pregnant women in conducting K4 visits in the Village Pinggirpapas Kalianget District Sumenep.

This research is descriptive research. This study population were all 3rd trimester of pregnant women in Pinggirpapas Village Kalianget District as many as 32 people, with 32 samples. Technique sampling is uses the total population. Variable in this research is education and perception of third trimester pregnant woman in doing $K 4$ visit. Data collection using questionnaires about education and perception of pregnant women in the visit of third trimester.

Result of research about education of pregnant mother shows that most of pregnant woman with elementary school that is much 22 people (68.8\%). Reseach on perception shows thaht most pregnant women have negative perception about $K 4$ visit that is as many as 21 people (65.6\%). The result of cross tabulation between education and perception of pregnant mother with elementary education had negative perception about K4 visit as many as 20 people (90.9\%). Pregnant women whose junior high school education had negative perceptions about visit of K4 1 person (33.3\%).

To increase the coverage of K4 visits in Pinggirpapas Village, Kalianget District, Sumenep needs to be socialized to pregnant women about the importance of $K 4$ visit so that pregnant women have positive perception about $K 4$ visit.
\end{abstract}

Keywords : pregnant women, trimester III, visits K4.

\section{PENDAHULUAN}

Pemeriksaan kehamilan adalah suatu tahapan untuk mencapai kehamilan yang baik dan sehat. Pemeriksaan kehamilan atau Antenatal Care (ANC) sangat dianjurkan untuk ibu hamil dalam mengontrol kesehatan janin dalam kandungan dan juga ibunya. Pemeriksaan kehamilan bisa dilaksanakan oleh dokter kandungan dan bidan paling sedikitnya pemeriksaan dilakukan 3 kali pada saat kehamilan yaitu pada usia kehamilan trimester I sebanyak 1 kali, trimester II sebanyak 1 kali dan pada kehamilan trimester III sebanyak 2 kali, apabila kehamilan dalam batas normal. Pemeriksaan kehamilan dilaksanakan sebulan sekali sampai usia 6 bulan, dalam satu bulan dilakukan dua kali pada usia 7 - 8 bulan dan satu minggu sekali pada saat usia kandungan mencapai usia 9 bulan.

Asuhan antenatal sangat penting guna mendukung proses alamiah tetap berlangsung normal pada saat kehamilan. Kehamilan bisa berubah menjadi masalah ataupun komplikasi setiap waktu. Pada saat ini umumnya diterima diterima jika setiap kehamilan beresiko bagi ibu. Berdasarkan data World Health Organization (WHO) pada tahun 2007, angka kematian ibu pada saat kehamilan, persalinan bahkan nifas mencapai 500.000 jiwa dan angka kematian bayi (AKB) sebanyak 10.000.000 jiwa, pada 
tahun 2009 jumlah kematian ibu mencapai 2650 orang. Angka kematian ibu (AKI) di Indonesia sangat besar bila dibandingkan dengan negara ASEAN yang lain, ini berarti kemampuan dalam pemberian layanan kesehatan harus diadakan perbaikan secara keseluruhan dan lebih baik.

Kematian maternal merupakan kematian seorang ibu pada saat hamil maupun dalam waktu 42 hari setelah berakhirnya kehamilan, tidak berpengaruh pada tempat atau usia kehamilan (Prawirohardjo, 2010). Berdasarkan Survei Demografi Kesehatan Indonesia (SDKI) tahun 2007, Jumlah angka Kematian Ibu mencapai 228 per 100.000 kelahiran hidup, Tahun 2009 AKI mencapai 357 per 100.000 kelahiran hidup tetapi tahun 2010 mencapai 263 per 100.000 kelahiran hidup. Untuk menurunkan AKI maka Ibu diperlukan upayaupaya yang terkait dengan kehamilan, kelahiran dan nifas (Manuaba, 2010).

Upaya nyata yang dilaksanakan pemerintah berdasarkan dengan Departeman Kesehatan Republik Indonesia dalam upaya penurunan AKI yaitu dengan cara menentukan bidan yang merupakan ujung tombak pemberi layanan kesehatan ibu dan bayi. untuk meningkatkan pelayanan, bidan-bidan wajib bekerja dengan profesional yaitu memberikan pelayanan kepada masyarakat dengan dengan standar yang telah ditetapkan pemerintah. Peranan bidan sebagai pusat pelayanan kesehatan ibu di Indonesia dalam pelaksanaan layanan kesehatan ibu selama Antenatal Care (ANC) sudah memberikan hasil yang baik. Kemampuan dan kompetensi yang wajib dimiliki oleh bidan untuk memberikan asuhan antenatal yaitu kemampuan dalam mengetahui kesejahteraan ibu dan bayinya serta mendeteksi komplikasi pada ibu dan janinnya. Upaya menunjang penurunan AKI di Indonesia maka pemerintah mempunyai target cakupan pelayanan Antenatal (K1) 95\% dan cakupan pelayanan antenatal K4 90\%. Untuk provinsi Jawa Timur mempunyai target cakupan pelayanan Antenatal (K1) 90\% dan capaian pelayanan Antenatal (K4) 85\%. (Depkes, RI, 2008).

Salah satu untuk mendeteksi komplikasi pada ibu dan janinnya adalah cakupan K4. Cakupan K4 adalah sebagai indikator dalam mengetahui jangkauan pelayanan antenatal dengan lengkap dan menilai tingkat perlindungan pada ibu hamil serta mengetahui kemampuan manajemen atau kelangsungan program KIA. Sarana pelayanan KIA yang mendukung kunjungan ibu dalam pemeriksaan kehamilannya yaitu buku KIA, peran petugas kesehatan, fasilitas pelayanan antenatal yang meliputi $7 \mathrm{~T}$ yaitu dengan pelaksanaan asuhan kebidanan atau biasa dikenal Antenatal Care (ANC).

K4 adalah Kontak minimal 4 kali pada saat masa kehamilan dalam memperoleh pelayanan antenatal, yang terdiri atas minimal 1 kali kontak saat trimester I, satu kali saat trimester II, dan dua kali saat trimester III. Cakupan K4 di bawah 95\% dibandingkan jumlah sasaran ibu hamil dalam kurun waktu satu tahun menunjukkan kualitas pelayanan antenatal yang tidak memadai. Rendahnya K4 menggambarkan kurangnya kesempatan untuk menjaring dan menangani risiko tinggi obstetric.

Berdasarkan data Profil Kesehatan Dinkes Kabupaten Sumenep didapatkan bahwa cakupan K4 tahun 2013 rata-rata sebesar 82,3\% dan di tahun 2014 didapatkan cakupan terendah K4 ialah Kecamatan Kalianget yaitu sebanyak 380 orang dari $644 \mathrm{ibu}$ hamil atau $64,5 \%$ dari target 95\%. Rendahnya kunjungan K4 menunjukkan rendahnya kesempatan untuk menjaring dan menangani resiko tinggi gangguan obstetrik. Salah satu dampak dari rendahnya cakupan K4 adalah kematian ibu dan bayi. Berdasarkan data di Puskesmas Kalianget didapatkan cakupan K4 yang paling rendah yaitu di Desa Pinggir Papas sebesar $24,6 \%$ dari target $95 \%$.

Rendahnya cakupan kunjungan K4 pada ibu hamil trimester III dipengaruhi oleh beberapa faktor, yaitu faktor predisposisi, faktor pendukung, dan faktor pendorong. Faktor predisposisinya adalah pendidikan, persepsi, dan pengetahuan. Faktor pendukungnya adalah adanya sarana kesehatan, dan faktor pendorongnya meliputi sikap dan perilaku petugas kesehatan.

Berdasarkan studi pendahuluan yang dilakukan oleh peneliti di Desa Pinggirpapas Kecamatan Kalianget Kabupaten Sumenep terhadap $10 \mathrm{ibu}$ hamil didapatkan data: $7 \mathrm{ibu}$ hamil yang tidak melakukan kunjungan $\mathrm{K} 4$, dan tingkat pendidikannya rendah serta memiliki persepsi yang negatif dalam melakukan kunjungan K4. Berdasarkan fenomena tersebut 
maka peneliti tertarik untuk melakukan penelitian lebih lanjut tentang gambaran pendidikan dan persepsi ibu hamil dalam melakukan kunjungan K4 di Desa Pinggirpapas Kecamatan Kalianget Kabupaten Sumenep.

\section{METODE}

Penelitian ini menggunakan rancangan penelitian deskriptif. Teknik sampling yang digunakan adalah total populasi. Populasi dalam penelitian ini merupakan semua ibu hamil trimester III di Desa Pinggirpapas Kecamatan Kalianget Kabupaten Sumenep pada bulan Desember 2014 - April 2015 sebanyak 32 orang, dengan jumlah sampel sebanyak 32 orang. Variabel dalam penelitian ini adalah pendidikan dan persepsi ibu hamil trimester III dalam melakukan kunjungan K4. Pengumpulan data menggunakan kuesioner tentang pendidikan dan persepsi ibu hamil dalam melakukan kunjungan trimester III.

\section{HASIL PENELITIAN}

\section{Usia Ibu Hamil}

Tabel 1. Karakteristik Ibu Hamil Berdasarkan Usia Di Desa Pinggirpapas Kecamatan Kalianget Kabupaten Sumenep

\begin{tabular}{cccc}
\hline No & Usia (Tahun) & Jumlah & Persentase \\
\hline 1. & $24-26$ & 8 & 25 \\
2 & $27-29$ & 7 & 21.8 \\
3. & $30-32$ & 8 & 18.8 \\
4. & $33-35$ & 6 & 25 \\
5. & $36-39$ & 3 & 9.4 \\
\hline & Jumlah & $\mathbf{3 2}$ & $\mathbf{1 0 0}$ \\
\hline
\end{tabular}

Berdasarkan tabel 1 menunjukkan hampir setengahnya $(25 \%)$ ibu hamil berusia $24-26$ tahun dan 33 - 35 tahun.
2. Kunjungan K4 Ibu Hamil

Tabel 2. Kunjungan K4 Ibu Hamil Di Desa Pinggirpapas Kecamatan Kalianget

\begin{tabular}{cccc}
\hline No & $\begin{array}{c}\text { Kunjungan } \\
\text { K4 }\end{array}$ & Jumlah & $\begin{array}{c}\text { Persentase } \\
(\mathbf{\%})\end{array}$ \\
\hline 1. & Melakukan & 10 & 31.2 \\
2 & $\begin{array}{c}\text { Tidak } \\
\text { melakukan }\end{array}$ & 22 & 68.8 \\
\hline & Jumlah & $\mathbf{3 2}$ & $\mathbf{1 0 0}$
\end{tabular}

Berdasarkan tabel 2 menunjukkan sebagian besar ibu hamil tidak melakukan kunjungan K4 yaitu sebanyak 22 orang $(68.75 \%)$.

\section{Pendidikan Ibu Hamil}

Tabel 3. Karakteristik Ibu Hamil Berdasarkan Tingkat Pendidikan Di Desa Pinggirpapas Kecamatan Kalianget Kabupaten Sumenep

\begin{tabular}{cccc}
\hline No & Pendidikan & Jumlah & Persentase \\
\hline 1. & SD & 22 & 68.8 \\
2. & SMP & 3 & 9.3 \\
3. & SMA & 6 & 18.8 \\
4. & PT & 1 & 3.1 \\
\hline & Jumlah & $\mathbf{3 2}$ & $\mathbf{1 0 0}$
\end{tabular}

Tabel 3 menunjukkan sebagian besar ibu hamil berpendidikan SD yaitu sebanyak 22 orang $(68.8 \%)$.

4. Persepsi Ibu Hamil

Tabel 4. Persepsi Ibu Hamil Trimester III Tentang Kunjungan K4 Di Desa Pinggirpapas Kecamatan kalianget

\begin{tabular}{cccc}
\hline No & Persepsi & Jumlah & Persentase (\%) \\
\hline 1. & Positif & 11 & 34.4 \\
2 & Negatif & 21 & 65.6 \\
\hline \multicolumn{2}{c}{ Jumlah } & $\mathbf{3 2}$ & $\mathbf{1 0 0}$
\end{tabular}

Tabel 4 menunjukkan sebagian besar ibu hamil memiliki persepsi negatif tentang kunjungan K4 yaitu sebanyak 21 orang $(65.6 \%)$.

\section{Pendidikan dengan kunjungan $\mathrm{K} 4$}

Tabel 5. Tabulasi Silang Pendidikan Dengan Kunjungan K4 Ibu Hamil Trimester III Di Desa Pinggirpapas Kecamatan Kalianget

\begin{tabular}{|c|c|c|c|c|c|c|c|}
\hline \multirow{3}{*}{ No } & \multirow{3}{*}{ Pendidikan } & \multicolumn{4}{|c|}{ Kunjungan K4 } & \multirow{2}{*}{\multicolumn{2}{|c|}{ Total }} \\
\hline & & \multicolumn{2}{|c|}{ Melakukan } & \multicolumn{2}{|c|}{ Tidak Melakukan } & & \\
\hline & & $\mathbf{F}$ & $\%$ & $\mathbf{F}$ & $\%$ & $\mathbf{F}$ & $\%$ \\
\hline 1 & SD & 1 & 4.55 & 21 & 95.45 & 22 & 100 \\
\hline 2 & SMP & 2 & 66.7 & 1 & 33.3 & 3 & 100 \\
\hline 3 & SMA & 6 & 100 & 0 & 0 & 6 & 100 \\
\hline 4 & PT & 1 & 100 & 0 & 0 & 1 & 100 \\
\hline & Jumlah & 10 & 31.25 & 22 & 68.75 & 32 & 100 \\
\hline
\end{tabular}

Berdasarkan tabel 5 sebagian besar ibu hamil Ibu hamil yang pendidikannya SMP 1 orang pendidikan SD tidak melakukan kunjungan K4 (33.3) yang tidak melakukan kunjungan K4. yaitu sebanyak 21 orang $(95.45 \%)$. 


\section{Persepsi dengan kunjungan $\mathrm{K} 4$}

Tabel 6. Tabulasi Silang Persepsi Dengan Kunjungan K4 di Desa Pinggirpapas Kecamatan Kalianget Kabupaten Sumenep

\begin{tabular}{cccccccc}
\hline \multirow{2}{*}{ No } & \multirow{3}{*}{ Persepsi } & \multicolumn{4}{c}{ Kunjungan K4 } & \multicolumn{2}{c}{ Total } \\
\cline { 3 - 7 } & & \multicolumn{2}{c}{ Melakukan } & \multicolumn{2}{c}{ Tidak Melakukan } & & \\
\cline { 3 - 7 } & & $\mathrm{F}$ & $\%$ & $\mathrm{f}$ & $\%$ & $\mathrm{f}$ & $\%$ \\
\hline 1 & Positif & 8 & 72.7 & 3 & 27.3 & 11 & 100 \\
2 & Negatif & 2 & 9.5 & 19 & 90.5 & 21 & 100 \\
\hline & Jumlah & $\mathbf{1 0}$ & $\mathbf{3 1 . 2 5}$ & $\mathbf{2 2}$ & $\mathbf{6 8 . 7 5}$ & $\mathbf{3 2}$ & $\mathbf{1 0 0}$ \\
\hline
\end{tabular}

Berdasarkan tabel 6 hampir seluruhnya sedangkan ibu hamil yang persepsinya negatif ibu hamil yang persepsinya positif melakukan tidak melakukan kunjungan K4 sebanyak 19 kunjungan K4 sebanyak 8 orang $(72.7 \%)$ orang $(68.75 \%)$.

\section{Pendidikan dengan persepsi ibu hamil tentang kunjungan K4}

Tabel 7. Tabulasi Silang Pendidikan Dan Persepsi Ibu Hamil Desa Pinggirpapas Kecamatan Kalianget Kabupaten sumenep

\begin{tabular}{|c|c|c|c|c|c|c|c|}
\hline \multirow{3}{*}{ No } & \multirow{3}{*}{ Pendidikan } & \multicolumn{4}{|c|}{ Persepsi } & \multirow{2}{*}{\multicolumn{2}{|c|}{ Total }} \\
\hline & & \multicolumn{2}{|c|}{ Positif } & \multicolumn{2}{|c|}{ Negatif } & & \\
\hline & & $f$ & $\%$ & $\mathrm{f}$ & $\%$ & $\mathrm{f}$ & $\%$ \\
\hline 1 & SD & 2 & 9.1 & 20 & 90.9 & 22 & 100 \\
\hline 2 & SMP & 2 & 66.7 & 1 & 33.3 & 3 & 100 \\
\hline 3 & SMA & 6 & 100 & 0 & 0 & 6 & 100 \\
\hline 4 & $\mathrm{PT}$ & 1 & 100 & 0 & 0 & 1 & 100 \\
\hline & Jumlah & 11 & 34.37 & 21 & 68.62 & 32 & 100 \\
\hline
\end{tabular}

Berdasarkan tabel 7 ibu hamil yang pendidikannya SD memiliki persepsi yang negatif tentang kunjungan K4 sebanyak 20 orang (90.9\%).

\section{PEMBAHASAN}

\section{Pendidikan}

Berdasarkan hasil penelitian yang dilakukan di Desa Pinggirpapas Kecamatan Kalianget Kabupaten Sumenep bahwa tingkat pendidikan ibu hamil masih rendah. Dari 32 ibu hamil yang diteliti, sebanyak 22 orang $(68.75 \%)$ tingkat pendidikannya SD. Indikator tingkat pendidikan terdiri dari tingkatan pendidikan dan penyesuaian jurusan. Jenjang pendidikan merupakan tahap pendidikan yang telah ditetapkan menurut tingkat perkembangan peserta didik, pencapaian tujuan, dan kemampuan yang dikembangkan terdiri dari pendidikan dasar, pendidikan menengah dan pendidikan tinggi (Notoatmodjo, 2003).

Berdasarkan studi awal yang dilakukan di Desa Pinggirpapas Kecamatan Kalianget Kabupaten Sumenep bahwa 7 dari 10 ibu hamil yang tidak melakukan kunjungan K4 berpendidikan rendah dan mempunyai persepsi yang negatif tentang kunjungan K4. Hasil studi awal tersebut sama dengan hasil penelitian yang dilakukan bahwa sebagian besar ibu hamil
Ibu hamil yang pendidikannya SMP yang memiliki persepsi negatif tentang kunjungan K4 1 orang $(33.3 \%)$.

berpendidikan rendah dan memiliki persepsi yang negatif tentang $\mathrm{K} 4$. Hal tersebut menyebabkan cakupan kunjungan K4 di Desa Pinggirpapas Kecamatan Kalianget Kabupaten Sumenep tidak memenuhi target yang diharapkan hanya $16(24.6 \%)$ dari 65 sasaran (Profil Puskesmas Kalianget, 2015).Kunjungan ibu hamil merupakan bertemunya ibu hamil dengan petugas kesehatan yang memberi pelayanan antenatal dalam memperoleh pemeriksaan kehamilan. Definisi kunjungan tidak mengandung arti bahwa selalu ibu hamil yang datang ke fasilitas pelayanan, melainkan dapat juga sebaliknya yaitu ibu hamil yang dikunjungi petugas kesehatan di rumahnya maupun di Posyandu (Sulistyawati, 2009).

Berdasarkan indikator cakupan pelayanan ibu hamil (K-4) bisa diketahui cakupan pelayanan antenatal secara lengkap (memenuhi standar pelayanan dan menepati waktu yang ditetapkan), yang menggambarkan tingkat perlindungan ibu hamil di suatu wilayah, disamping menggambarkan kemampuan manajemen maupun kelangsungan program 